\title{
The Form and Content of Children's Poetry and Games on a Kaleidoscopic Cultural Terrain
}

\author{
Tsitsi Nyoni \\ The Department of Teacher Development at Great Zimbabwe University, P.O. Box 1235, Masvingo, Zimbabwe \\ Mika Nyoni \\ The Curriculum Studies Department at Great Zimbabwe University, P.O. Box 1235, Masvingo, Zimbabwe
}

\begin{abstract}
This research sought to look into the form and content of children's poetry and games in Shona. It was premised on the view that these aspects are part and parcel of the rich African heritage of orature and are an important component of Shona indigenous knowledge systems, hence these cannot be simply ignored more so when it comes to the process of socialization. The objective was to analyze critically these so-called play poems and games in terms of their form and content and see what is embedded in them. Data was gathered through observation as children went about their business of play. The research concluded that these poems and games cannot be simply treated as child's play as their content is 'loaded'. They are actually a silent but powerful vehicle for the inculcation of certain values and attitudes that influence the children's own lives later whether positively or negatively, at home or away from their comfort zones in the global village. As part of the African Indigenous Knowledge System, which has sustained us for centuries such intangible heritage should not be let to just spill from our cultural hands. The various forms they take also allow children to simulate real life situations and learn adult roles vicariously and thus prepare them for the challenges life proffers not as shadows of other people but as proud beings who can cast their own shadows on the kaleidoscopic cultural terrain.
\end{abstract}

Index Terms - form and content, children's literature, Orature, changing culture

\section{INTRODUCTION}

Children's poetry (also called play-songs, nursery songs, nursery rhymes) and games are part of the indigenous knowledge of the particular society in which they are recited or done respectively. Of late, interest has risen in research on indigenous knowledge with researchers targeting various aspects as the following examples show: songs as ways of knowing (Mapara and Nyota, 2008); language as indigenous knowledge (Mapara and Nyota, 2007); relevance to technology (Kunnie 2000; Pikirayi, 2000), indigenous ways of knowing (Goduka, 2000) and relevance of indigenous knowledge in the teaching and learning of Mathematics (Madusise, 2010).

So far, the researchers have not come across many researches that have attempted to look at the form and content of children's poetry and games in Shona per se except one done by Nyota and Mapara (2008) cited earlier on which only sampled pre-colonial ones and not those in currency or those composed or adapted after during or after colonization. These children's poetry and games, it should be noted, are part of Shona Oral Literature, as children's literature, which Hunt (1994) argues is "a powerful literature, and ... that such power cannot be neutral or innocent or trivial" (p3). What Hunt implies here is that, children's literature somehow does influence the child's worldview in terms of behavior or attitude. This in turn, by implication, means that children's poetry and games (being part of children's literature) also have some effect on the children as they recite and do them respectively even though people in the immediate culture might be tempted to think that childhood is a period of life free of responsibility and susceptible to education.

The above view is also shared by Trovato, in his article 'Ban those killer Nursery Songs' in The Sunday Times of April 11, 2010. He points out that children's poems (nursery songs) instill certain attitudes into the children, so they cannot be just taken lightly. What he is referring to here is their content which he argues is 'loaded'. Examples are given of English children's poems to justify his argument. 'Baa baa black sheep' is one of them and it shall be given in full below for reference later:

Baa baa black sheep have you any wool?

Yes Sir, Yes sir, three bags full.

One for the master one for the dame

And one for the little boy who lives down the lane.

From Trovato's point of view, the above poem instills the belief that black sheep are not the same as 'normal' sheep, not merely because they can talk, but because they are black. The use of 'master' and 'dame' presents a subservient tone and alacrity with which the sheep responds to demands for its wool to suggest that it has been oppressed for some time. The same goes for 'Humpty Dumpty' which he argues promotes hate speech directed at fat people yet sometimes 
obesity is due to heredity and not someone's fault. Even violence, he believes, can be incited through the seemingly "innocent" rhymes.

The fact that no research known to the researchers has looked at the form and content of children's poetry and games in Shona in depth and views such as those raised by Hunt (1994) and Trovato (2010) above, that triggered the researchers into having a look at the form and content of children's poetry and games in Shona. While Trovato brings out only the negatives in terms of content of similar poems in English, the researchers would want to find out what form these poems and games take in Shona, interrogate the content and see whether positive values do not come out of these as well.

\section{CONCEPTUAL FRAMEWORK}

\section{Children's Poetry and games}

Children's poetry and games are part of what is called Indigenous knowledge. Madusise (2010) defines IK (Indigenous knowledge) as: "context localized knowledge which can be preserved, transferred or transmitted from one generation to another" (p4).

She goes on to give a variety of terms used to refer to it, denoting slightly different meanings to different users of the concept such as "traditional knowledge", "traditional cultural knowledge" or "traditional environmental knowledge". She further argues that there is consensus among those using the various terms that such knowledge is linked to a specific place, culture or society and is dynamic in nature (Madusise, $2010 \mathrm{p} 4$ ). This argument is quite relevant to children's poetry and games as these vary according to societies and change with the times as shall be illustrated later in this research. In the context of this research, this indigenous knowledge is mainly found in orature of which children's poetry and games are a component as its definition explicitly shows:

Those utterances whether spoken, recited or sung, whose composition and performance exhibit to an appreciable degree the artistic characteristics of accurate observation, sound imagination and ingenious expression. (Nandwa and Bukenya, 1983: p1)

The utterances referred to above include traditional narratives, proverbs, recitations (poems), and songs among others (Finnegan, 1970). Nandwa and Bukenya [1983] further posit that the orality of the utterances emanates from the fact that in their natural state, they are composed and performed through the spoken word or by word of mouth, which is what 'oral' entails. To further show that children's poetry and games should be viewed as orature, Krog (1966:169) also makes a justification for their being recorded as poetry because of "their structure in written form, that is ,their verse form, rhyme scheme, onomatopoeia and chorus that is repeated after each line" (p169).

The above discussion clearly shows that children's poetry and games, fit into the oral literature genre as they, like all literature does, teach and delight, as they move the children by appealing to both their understanding and feelings. Those that excite, excite them, while those that instill feelings contrary to excitement for example fear, do so.

Chimhundu and Chabata (2008) call children's poetry nhambe (play) from the verb kutamba (to play). Literally they are just viewed as play but as part of Indigenous knowledge researches done by Nyota and Mapara (2008), Madusise (2008), Gokuda (2000), Kunnie (2000), Pikirayi (2000) clearly point to the fact that they are relevant and useful in one way or the other. They are a legacy which touches an all aspects of life in the context in which they are done. Nyota and Mapara (2008) call the poems play songs and view them as indigenous ways of knowing and rich sources of knowledge. They are thus part of the rich literally heritage of children's poetry in oral literature circles.

\section{The role of Children's Poetry and Games}

Stebbing (1999) points out that the major role of children's games and poetry is primary socialization. This is so important in that, when they get to the world of education, it becomes the golden link between home and school. This link is vital in the view that teachers can start with what children know and can do; then build on that since children enjoy moving from the known to the unknown, which allows for building of self-confidence. Thompson (2001) also notes that children's poetry and games stimulate children to learn and help them develop fast in their mother tongue (in this case ChiShona) by providing an opportunity for them to use their language.

Children's poetry and games are also a rich source of their cultural heritage, language, traditions and moral values (Nyota and Mapara 2008, Stebbing 1999). In as far as learning pf values and virtues that may be useful later on in life is concerned, Nyota and Mapara (2008) put forth a very strong argument that:

Shona traditional children's games and songs (poems) lead to and provide a rich environment or social context which sustains the flowering of children's curiosity and exploration on their immediate world as they play. (p189)

Thus as they explore their environment they learn that it is good to play with others. The virtues and values alluded to earlier on in the discussion, such as good behavior, honesty, hard work, healthy competition, leading and being led, handling of success or failure etc, are in turn instilled into the children vicariously as they interact in play. This helps build foundation for the philosophy of ubuntu (humanness) rooted in African culture, characterized by qualities such as responsibility, honesty, justice, trustworthiness, a cooperative spirit, hard work etc (Mavhunga 2008; Nziramasanga, 1999). This philosophy is also described else where as a philosophy of shared humanity well expressed in the Nguni language maxim; a person is a person through other persons (Heyns and Stefiszyn, 2008) relevant to this study is the fact that we become what we become through interacting with others who helps us become human. Thus as children interact in games and through poetry (most are performed in groups) their sense of being emerges and develops. 
Theories on child development attest to the importance of play in child development. For example Froebel has this to say about play:

The plays of childhood are germinal leaves of all late life, for the whole man is, developed and shown in these, in his tenderest dispositions, in his innermost tendencies (cited in Morrison, 1998: p49).

\section{MethodolOGY}

Data was gathered through observation as children went about their business of play. The researcher would simply write down or (using cellular phones) audio- or video-record the recitals and games without disturbing their play. Some of the poems and games were gathered as children played at break time during Teaching Practice visits in both rural and urban school environments. The verbal content captured in this article only represents one element. Other elements at the performer's disposal such as the co-performers, the audience and the non-verbal aspects are unfortunately lost. As noted by Finnegan (1970)

...the connection between transmission and very existence is a much more intimate one [than in written literature]...without its oral realization and direct rendition by singer or speaker, an unwritten literary piece cannot easily be said to have any continued or independent existence at all ... (p2)

With the above in mind the authors saw it prudent to provide as much background information as possible because in the case of oral literature the bare words cannot be left to speak for themselves for the simple reason that in the actual literary work so much else is necessarily and intimately involved...(Finnegan,1970:p15).

\section{Analysis of Poems and Games}

Selected children's poems and games will be analyzed below, focus being mainly on their form and content. However, before the analysis a distinction should be made here between games and poems. Games are differentiated from poems in this research by the nature of their performance. With games some form of drama or group involvement is a prerequisite. While poems can be recited individually; with a game partner or group is necessary so that some form of interaction is possible. For example with the game Sape Sape (clap, clap) a partner is required for the clapping, while for Sarura Wako a group is necessary so that the individual can then choose a partner from amongst the group members. For the purpose of this research poems and games originating in the pre-colonial era shall be referred to as traditional while those that emanated thereafter will be referred to as modern.

Poems and games originating from the pre-colonial era

Mangwana dzinani? (Who herds them tomorrow?)

Mangwana dzina Toriro (Tomorrow it's Toriro's turn)

Toriro dumbu guru gadzike (Toriro of the big tummy)

In terms of content, this is mainly used to remind the person taking over the dzoro (duty) to herd cattle. It is like passing on the baton stick in a relay. Toriro stands for the name of the person next on duty. Reference to a big tummy is meant to make the whole process humorous. The Shona believe that when work is presented in an interesting manner, it makes it acceptable as the load is made to feel lighter. Thus the task becomes quite welcome. Values instilled into the children are that of duty consciousness, responsibility and co-operation which are all part of the spirit of ubuntu (humanness) (Mavhunga, 2008; Nziramasanga, 1999). More importantly it should be noted that the pronoun them refers only to cattle here and not any other animal. This teaches the young boys that cattle are an important economic assert useful in many ways in African culture where they play a crucial part when it comes to issues such as lobola, burials of adults where one is killed as nhevedzo [send off token], during kurova guva, as payment for an avenging spirit (ngozi) and as draught power for all agricultural activities.

The poem takes the form of questions whose answers are known anyway because those involved are aware of who comes next as per their duty roaster.

Mwana wachema vakoma (The baby is crying, sister)

Mwana wenyu wachema vakoma

Wachemera mai vakaenda

Vakaenda kwaChidyamupunga

Chidyamupunga magaka aora

Aorera mhiri kwaMungezi

KwaMungezi kune banga jena

Banga jena rekucheka nyama

Nyama kwayo ndeyeparuware

Yapasi inozara mavhu

Heino njiva...

$\mathrm{Hu}$-u!

Inogurukuta

Hu-u!

Nechana munyasi

$\mathrm{Hu}$-u! 


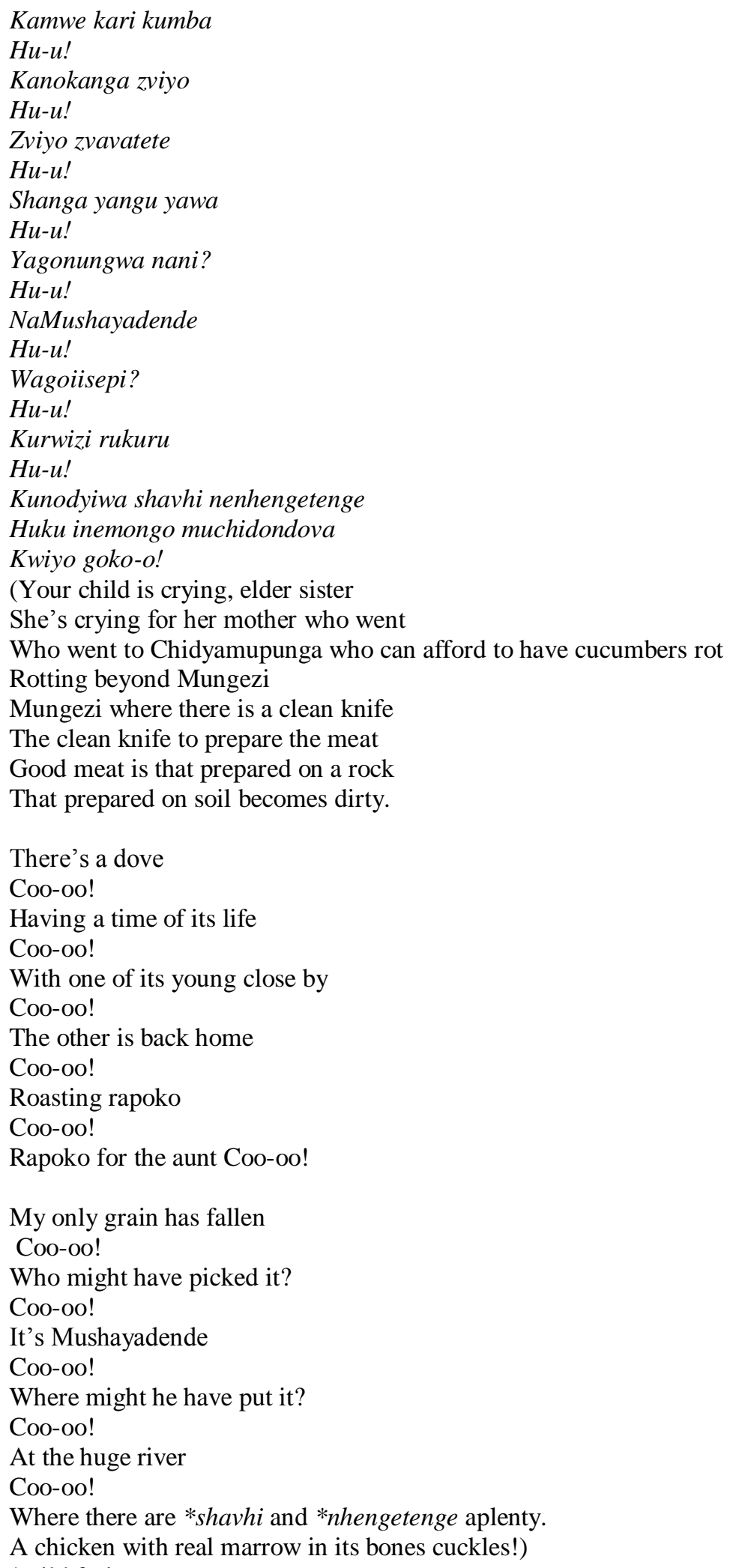

*wild fruits

This poem is a lullaby which in terms of content is pregnant. It touches on various aspects such as natural phenomena, relationships, birds' world, wild fruits, grains and others that relate to the Shona people's way of life. The baby cries for a 'mother' (wachemera mai vakaenda) who has gone to Chidyamupunga across the Mungezi river. The importance of a mother figure is emphasized from this tender age. In Shona culture the mother is a pillar of the home as encapsulated in the adage, Musha mukadzi, which literally means 'A home is a woman'.Without a mother in the home everything crumbles. Mungezi River is a natural phenomenon, representative of the fact that children should know the world around them. Reference is also made to rice (mupunga) a cereal, and cucumbers (magaka) a vegetable/fruit, which are 
food stuffs that are grown in the fields. Crop farming is part and parcel of the Shona economic system. Thus reference made to the various crops denotes the importance. There is also evidence of high productivity as Chidyamupunga can afford to have cucumbers rot,a sign of his being not just an ordinary farmer, but a farmer par excellence (hurudza in Shona). The name literally means 'the one who eats rice'. Rice is regarded as a delicacy in Zimbabwe where the staple food is sadza. The latter is partaken by the 'ordinary' while rice is for the chosen few hence Chidyamupunga is a cut above the rest and should therefore be emulated.

The poem sensuous, therefore living, vivid and picturesque and quite appealing especially to the young: there are cucumbers that rot (appealing to the sense of smell), the cooing dove (appealing to the sense of hearing), the clean knife (appealing to the sense of sight) and the eating of shavhi and nhengetenge. Children also learn about the function of everyday but important utensils/tools such as the knife (that of cutting, meat in this case) and are also alerted to the need for good hygienic practice so crucial to their life as they are urged to take care when cutting the meat, lest they spoil it, by cutting it on soil:

Banga jena rokucheka nyama

Nyama kwayo ndeyaparuware

Yapasi inozara mavhu

(The clean knife for cutting meat

Good meat is that cut on a rock bed)

That which is cut on the ground is spoiled by soil).

The reference to njiva (dove) introduces the children to the birds' world; while the mention of zviyo (rapoko) introduces them to a drought resistant crop which has to be roasted, kukangwa before being ground into rapoko meal. The last line of the poem makes reference to wild fruits that are found by the riverside shavhi and nhengetenge. The trees require lots of water (so the roots get this from the river), are evergreen, producing lots of fruits that are juicy and delicious. Young children love these and feast on them (when in season) while herding cattle. Thus by continuously reciting the lullaby; important aspects of life that children need to know are reinforced; and children's awareness of these is raised. It should be noted that the consumers of such art are not the child singers but also all those within hearing range of the singer. One is reminded of the poem 'The Solitary Reaper' by William Wordsworth where the reaper was singing to herself but moved a listener she did not even see.

In terms of form, the poem has lots of cross linking where the word or phrase ending the preceding line begins the subsequent line thus giving the poem/song compactness and fluidity.

... wachema vakoma

Wachemera .... vakaenda

Vakaenda ..... kwaChidyamupunga

Chidyamupunga ...

The top line ends with "... has cried sister", the next one begins with "has cried for a mother and ends with "who has gone", then the next one begins with Chidyamupunga. Final linking also provides rhythm in the last part of the poem with the repetition of $h u-u$, imitating the dove's cooing where njiva (dove) comes in. These linkages and repetitions make the poem quite exciting to recite. This, children enjoy since they learn quickly but also forget quickly hence the repetitions keep refreshing their memory (Thompson, 2001). The soothing sound from the rhythm in the end quietens the baby who might even fall asleep.

The poem makes use of the tongue in chick technique to comment on some mothering practices. The young sister sings about the child crying about her mother who has gone mhiri kwaMungezi, a hyperbolic statement, yet she is only working a few meters away. This can be seen as a subtle way of rebuking the elder sister for 'abandoning' the baby for her chores. We can also look at it as a complaint on the part of the baby minder. It is not always nice for the young baby minder to be disturbed in her business of play for a long time to sing for the sister's baby until she sleeps while it is strapped on her back. It should be noted that such baby minders are almost always the youngest in the family who are deemed to be too young to do the heavier tasks the other members of the family will be doing such as weeding and pounding. Therefore carrying the baby on the young minder's back is really some task hence the tinge of complaint noted in the song.

Mwedzi wagara (The moon has risen)

Mwedzi wagara Ndira

Pamusi wemba Ndira

Nhasi uri pano Ndira

Wemba wemba Ndira

Kwigo Ndira

Ptu! tenderekedziwe

Enda nourwere hwangu!

(The moon has risen, for the first time

On top of the house for the first time

Today its here for the first time

Of the house of the house for the first time 
Up it goes for the first time

(the child spits) moonrise

Carry my ailments with you when you go!)

In terms of content, the poem is about seasons. Every time the moon appears starting with a quarter moon, followed by a half moon and finally the full moon, the children know another month has gone by. Children normally recite the poem the first time they see the moon rising. Making a wish at the end of the poem is in the belief in African culture that for everything there is a season, and a new season comes with new things, normally good things. So illness is not good, therefore it should go with the full moon and the new moon when it comes, should obviously bring good things.

\section{Games}

Sarura wako (Make your choice)

In this game the child who is making the choice goes on to describe the girl or boy of his or her choice using adjectives and adjectival phrases that he or she thinks bring out the best qualities or characteristics of his or her choice as follows:

Leader: Sarura wako

Respondents:Kadeyadeya ane ndoro chena.

Leader:Wangu mutsvuku

Respondents:Kadeyadeya ane ndoro chena.

Leader:Ane bvudzi dema

Respondents:Kadeyadeya ane ndoro chena.

Leader:Ane mwoyo chena

Respondents:Kadeyadeya ane ndoro chena.

(Leader: Make your choice

Respondents: Take your time. The one with a patch of white hair.

Leader: Mine is light skinned...

Respondents: Take your time. The one with a patch of white hair.

Leader: Has black hair

Respondents: Take your time. The one with a patch of white hair.

Leader: Is very kindhearted

Respondents: Take your time. The one with a patch of white hair.)

This goes on for a while, then the choice is made. It is like dramatization of how one chooses a partner during courtship. This is closely linked to the Shona custom of courtship and marriage where one should marry those they know as encapsulated in the proverb Rooranai vematongo (Marry from the vicinity i.e. those whose background one is familiar with).Apart from considering physical qualities or features (outward beauty), the young are encouraged this early to look at virtues of ubuntu or humanness such as kindheartedness, cleanliness, responsibility and so forth, what one can call inner beauty. Another important virtue also learnt through this game is that those who are related should not marry, because if during the game one chooses a relative, others will laugh at him or her to show that it is a taboo (Hodza, 1984).

This game thus makes it easy for the children when they become young adults to make informed choices during courtship. One important fact is that as the children go through their choices the one who will remain on the shelf is described as zai rakavora (a rotten egg).Such a child will strive in future to be likeable and therefore choosable and avoid the ignominy of being left unchosen on the shelf. In a way therefore the game has a behavior regulatory function.

Mapere (Hyenas)

Another interesting game that children enjoy is mapere which takes the form of a challenge where ducking, dodging and running fast so as not to be caught is crucial. Children are divided into two groups for the children and the other for the hyenas. The mother then calls the children to come over to her and the children run fast dodging the hyenas in order to get to the mother and safety. If caught by the hyenas, the child automatically becomes a hyena and the game goes on:

Mai:Vana vana!

Vana: Mhai!

Mai:Huyai!

Vana: Tinotya!

Mai:

Munotyeiko?

Vana:Mapere

Mai:Mapere akapera kuenda Hwedza huyai henyu!

(Mother:Children,Children!

Children:Mother!

Mother:Come over!

Children:We're afraid!

Mother:Afraid of what? 
Children:Hyenas!

Mother:The hyenas all went to Hwedza, come over.)

The children then run over to the mother. Clever children will get to the mother for protection while the not- soclever will be caught and become part of the hyenas group. This trains children to be aware of the need to be alert to the dangers of life and reinforces the importance of the mother figure in one's life and the importance of obedience.

Tipeiwo mvura yokumwa (May we have some water to drink?)

Tipeiwo mvura yokumwa?

Torai! Torai!

(Can we have some water to drink?

Have it! Have it!)

The recitation can be done by the child individually or with other children. The children dance in rhythm to the recitation while they dance and dramatize asking for water and drinking it. The main point being emphasized through this game is that people should be generous and hospitable, more so with water which is something that one cannot deprive someone of since it is a free gift from God. It should be given freely hence the repeating of Torai, torai. The game also gives the children the opportunity to acquire appropriate register: the children ask for the water, they do not demand for it. They also interestingly do not ask to buy it because as a free gift from God it should be given free.

The following recitations/games are very popular with infants especially just before toddlerhood:

a) Amiramira nhanha!

Kwasara kufamba!

(The child is standing!

What remains is walking!)

b) Ndee nhanha ndee

Ndee kuna mai ndee

Ndee kuna baba ndee

Ndee kuna mbuya ndee

Ndee kuna sekuru ndee

Ndee kuna sisi ndee

Ndee kuna bhudhi ndee etc

(Walk child, walk

Walk to mother, walk

Walk to father, walk

Walk to granny, walk

Walk to grandpa, walk

Walk to sister, walk

Walk to brother, walk etc)

The use of motherese in both poems is meant to bring the older child or adult closer to the infant. Nhanha is motherese for mwana (child).The adult or older child recites the poem while engaging the child in some form of drama. $\mathrm{He}$ or she praises the child for being able to stand and tells him or her that what remains is walking (poem (a).There is Skinnerian shaping as the child is rewarded for each little step he or she achieves. As soon as the child makes the step the adult or older child goes on to encourage the child further by directing him or her to various people in the family that is father, grandmother, grandfather, sister, brother etc this way the child not only gets the practice but also appreciates kinship ties from the onset. At the moment each of the relatives is ready to catch the inexperienced walker the same way they will later in life physically, socially and emotionally as need arises. The repetitions and motherese appeal to the young ears which also helps to spur the child on. It should be pointed out that as the child makes these first steps the whole family will be involved in the singing and clapping, thus instilling the spirit of familihood.

Poems and games from the colonial and post colonial era

These can be easily identified due to the linguistic code and changing images incorporated in them. The changes are due to the changing environment due to education, westernization, technology and urbanization. Thus like all other oral art forms, children's poetry and games reflect this dynamism. Researchers at the Universities of East London, Sheffield and the Institute of Education, for instance, discovered that:

children still enjoy old school yard favourite games children still spend their school break times singing the songs that have been circulating for decades, although they sometimes update them by inserting references to the latest pop stars and soap characters.(The Herald, 17 March 2011).

The few examples analyzed below will clearly show that what the researchers discovered in Britain also applies to the Zimbabwean scenario. Junod's 1913 observations on African narrative art also applies to present day children's oral art:

New elements are also introduced; owing to the tendency of Native (sic) story tellers always to apply circumstances of their environment to the narration. This is one of the charms of the Native tales. They are living, viz., they are not told as they are past and remote events in an abstract pattern, but considered as happening amongst hearers 
themselves...so all the new objects brought by civilization (sic) are, without the slightest difficulty, made use by the narrator...(cited in Finnegan, 1970: p9).

Ndakatumwa kumabheka (I was sent to the tuckshops)

Ndakatumwa kumabheka

Kunotenga masamba

Ndikasangana nejaya

Richiti ndinokuda

Ndikati,sve-e handikudi

Ndinoda Mupostori

Anonditengera gemenzi

Nemudonzvo wesirivha

Kana hondo yauya

Mhai, ndovanda mundebvu

Ini ndovanda mundebvu!

Ini ndovanda mundebvu!

(I was sent to the tuckshops

To buy tea leaves

And I met a young man

Who said he loved me

And I said No, I don't love you

I love an 'apostle'

Who buys me a church robe

And a silver staff.

If a war breaks out

Mother, I hide in his lush beard

I hide in his lush beard!

Yes, I hide in his lush beard!)

The recitation is in the form of a game played by children in pairs. They clap each other's hands in style and rhythm to the recitation. The content comes from the advent of industrialization and urbanization which brought with it tuck shops/ kiosks. These are a modern phenomenon brought in by enterprising business minded people who took advantage of customers who did not want to walk to the shops which in most cases were some distance away from the residential areas. Thus the tuck shops were strategically located within the residential areas stocked with daily provisions like bread hence their characterization as kumabheka (from baker) in the poem or song. The scene portrayed in the poem represents a courtship scene in a different environment: on one's way to the tuck-shop, as opposed to the traditional environments where girls and boys would meet and propose during the full moon, at the well or in the forest fetching firewood (Hodza, 1984).

In a satiric manner, the young man is turned down because the girl loves a member of the apostolic sect whose men folk's trademark is the beard and a long wooden or silver staff. What makes the poem satirical is that she loves a man from this sect because if a war breaks out she will hide in the lush beard, implying that the beards are so bushy and long that one can hide and not be seen by the enemy. One cannot help but laugh at the picture portrayed here. The above poem is also in stuck contrast to the traditional courtship poem Sarura Wako analyzed earlier on. There was no reference to material things as focus was on beauty both physical and inward. Only wealthy members of the apostolic sect can afford to buy a silver staff, the rest carry wooden ones, hence in the modern poem, there lies implicitly, admiration for material things. One cannot just fall in love with any Tom and Dick, but someone who is well to do and can protect and provide for materially like the chosen apostolic faith man. In the poem we discern gender stereotyping: the man is supposed to protect and provide for the delicate and dependent woman .We also discern the negative perception Zimbabwean society generally has towards members of this sect as reflected in the children's work which as earlier alluded to by Trovato, is far from neutral or trivial. Children do not live on an island but are part and parcel of a society which might have its own tolerances, intolerances and prejudices.

The advent of western education also brought in creation of new children's poems and games which capture the new register of education and the subjects among other things. The following examples are all linked to this:

Zvandadzidza pano,maiwe!

Zvandishamisa!

Zvandadzidza pano,maiwe!

Zvandishamisa!

Musoro kuti head

Meso kuti eyes

Zheve kuti ears

Mhino kuti nose 


\author{
Muromo kuti mouth \\ Huro kuti neck \\ Mafudzi kuti shoulders \\ Chifuva kuti chest \\ Dumbu kuti stomach \\ Chivuno kuti waist \\ Mabvi kuti knees \\ Maiwe!Zvandishamisa!
}

(What I have learnt here, mother has enthralled me...)

The child goes on to mention and touch the body parts from the head downwards, in the order in which they come on his or her body. What fascinates the child are the English names for she already knows the Shona ones. The codemixing is very effective here as the child begins with the mother tongue then switches on to the new language which continues to surprise him or her as the English names are mentioned. The juxtaposition of the parts of the body in the two languages (Shona and English) helps the children master the concept being learnt as it is first given in the mother tongue then reinforced in the target language which in this case is English. This also links well with what is encouraged in the Zimbabwe education policy that at infant level children should be taught first in their mother tongue before the second language comes in (Zimbabwe Education Act of 1987 as amended in 2006).

Mathematics has also not been spared of the children's poetic ingenuity as the following poem shows whose English equivalent is 'Five Little Ducks!' shows:

Madhadha Mashanu (Five Ducks)

Madhadha five ari pamutsetse

Ndikabvisa one kunosara four

Madhadha four ari pamutsetse

Ndikabvisa one kunosara three

Madhadha three ari pamutsetse

Ndikabvisa one kunosara two

Madhadha two ari pamutsetse

Ndikabvisa one kunosara one

Dhadha one riri pamutsetse

Ndikabvisa one kunosara zero-o-o!

(Five ducks in a row

If I remove one, four remain

Four ducks in a row

If I remove one, three remain

Three ducks in a row

If I remove one, two remain

Two ducks in a row

If I remove one, one remain

One duck in a row

If I remove one, zero-o remains!

Typical of the bilingual speech community in which the children operate, this poem also has code-mixing as one of its distinguishing characteristics. The numbers are all in English.

Industrialization also brought with it new forms and systems of health as the following poem explicitly shows:

Amina

Amina,Amina kadeya

Kungovheya

Amina wandishamisa

P.O.Box Marandellas, Marandellas

Dhumbembe dhumbembe dhumbembe

Amina's ju-u jekiseni

(Amina,Amina of the rickets Moving about unsteadily Amina, you surprise me P.O.Box Marandellas, Marandellas You go there! You go there! You go there! Amina be immunized)

The poem shows that the children are aware of the importance of immunization. They are surprised that Amina has 'deformed' legs which could have been prevented through immunization (Polio can cause one to have bent legs yet there is immunization to prevent this). In this case Amina walks unsteadily kungovheya due to the problems with her legs (she has rickets) The advice being given to her is that she should go to Marandellas (Marondera town) and get medical attention. The form of the poem is that of nhango (didactic poem) because of its advisory nature which is similar to that role played by aunts and uncles in the Shona traditional set up. These advise girls and boys on matters of life (Hodza,1984) just like the children are doing to Amina. Use of the Post Office box makes reference to letter writing 
also a western phenomenon which is an indication of western influence on the culture of the people from which the poem was composed. External influence is also discernible from the persona's exotic name as well as the Anglicized town name: Marondera is anglicized to 'Marandellas'. This shows the colonial influence-colonization led to the conquered losing even the names of geographical features in their environment to their conquerors and this is sadly encapsulated in the children's songs to show how deep rooted colonization had become.

Another interesting poem is Tambirai Masoja (Welcome the soldiers) which goes as follows:

Tambirai masoja

Ahwinha

Adzoka

Abva kuhondo

(Welcome the soldiers! They've won! They're back! They're back from war!)

The youngsters line up like soldiers on a parade and march excitedly and triumphantly showing that they are a victorious army. They repeatedly chant as they march in unison to the left -right style of an army. This form of the poem is typical of children's poetry which as the analysis made has shown characterized by repetitions, cross linking, chanting and onomatopoeia among other features

\section{CONCLUSION}

The above analysis ,though by no means exhaustive taking cognizance of the expansive and fluid nature of children's oral literature, has shown that some traditional poems and games are still being recited and done respectively by children but there are also novel creations that have come incorporating new images brought in by a kaleidoscopic cultural terrain. Their form and content still touch on both material and non-material culture of the people. The dynamism that is inherent in other oral forms of art is also evident in children's poetry and games. Themes like hospitality, courtship, advice, team-work, ubuntu (humanhood) among others, continue to inform children's poetry and games. Since children do not live alone on their island free from adult influence, their art reflects the norms and values of wider society as well as, sadly, its vices such as prejudice and intolerance.

\section{REFERENCES}

[1] Chimhundu, H. and Chabata, E. (2007). Duramazwi Redudziramutauro nouvaranomwe. Gweru: Mambo Press.

[2] Finnegan,R. (1964).Oral Literature in Africa. Cambridge: Claredon Press.

[3] Hodza, A. C. and G. Fortune. (1979). Shona Praise Poetry. Oxford: Claredon University Press.

[4] Hunt, P. (1994). An Introduction to Children's Literature. Oxford: Oxford University Press.

[5] Goduka,I. (2000). 'Indigenous Ways of Knowing: Affirming a Legacy' in Chiwome, E.M. et al (Eds) Indigenous Knowledge and Technology in African and Diasporan Communities. Harare: Southern African Association for Culture and Development Studies pages 134-145.

[6] Heyns, C. and Stefiszyn, K. (2008). Human Rights, Peace and Justice in Africa: A Reader. Mutare: Africa University.

[7] Kunnie,J. (2000). 'Developing Indigenous Knowledge and Technology in Africa and Diasporan Communities. Harare: Southern African Association for Culture and Development Studies pages 33-44.

[8] Krog, E. W. (Ed) (1966). African Literature in Rhodesia. Gwelo: Mambo Press.

[9] 'Children's Playground Games and Songs in the New Media Age' in The Herald, 17 March 2011.Harare:Zimpapers.

[10] Madusise,S. (2010). Exploring the Potential of Using Basket and Mat Weaving in the Teaching and Learning of Mathematics. Occasional Paper No. 64

[11] Mapanje,J and White, L.(1984). Oral Poetry from Africa. An Anthology. New York: Longman.

[12] Mapara,J. and Nyota, S. (2007). Language as Indigenous Knowledge. Cape Town: Centre for Advanced Studies of African Society.

[13] Mapara,J. and Nyota, S. (2008). 'Shona Traditional Children's Games and Play: Indigenous Ways of Knowing' in The Journal of Pan-African Studies, Vol. 2 Number 4,June,2008 pages 189-200.

[14] Mavhunga,P. (2008). 'Africanizing the Curriculum: A case for Zimbabwe' in The Zimbabwe Journal of Educational Research Vol. 20 Number 1,March 2008.Harare: Human Resource Research Centre.

[15] Nandwa, J. and Bukenya, A. (1983). African Oral Literature for Schools. Nairobi: Longman Kenya Ltd.

[16] Nziramasanga, (1999). Report of the Presidential Commission of Inquiry into Education and Training. Harare: Government Printers.

[17] Pikirayi, I.(2000). 'The Contribution of the Indigenous Technological Base in the Transformation of African Communities in the Zimbabwean Plateau During the First and Second Millennium AD' in Chiwome,E.M. et al (Eds) Indigenous Knowledge and Technology in African and Diasporan Communities. Harare: Southern African Association for Culture and Development Studies.

[18] Quiller-Couch, A. (ed.) (1919). The Oxford Book of English Verse: 1250-1900. Oxford: Oxford University Press.

[19] Stebbing, B. (1999). Learning Through Play: A Manual for Early Childhood Educators. Harare: UNICEF.

[20] The Zimbabwe Education Act of 1987 as amended in 2006.Harare: Government Printers.

[21] Trovato, B. (2010). 'Ban those killer Nursery Songs' in The Sunday Times April 11 2010. East London: Avusa Media. 
Tsitsi Nyoni is currently a lecturer in ChiShona at Great Zimbabwe University, Faculty of Education, Department of Teacher Development. Her main research interests are in Sociolinguistics, Literature (including Children's Literature), Lexicography and Contemporary issues such as Gender and Child abuse. She has published a number of articles in these areas and two chapters in a book on Shona Grammar (2012). She has also presented papers on Time Management and Communication Skills mostly to students at Teachers' Colleges, Universities and various interdenominational fora. She has also been involved in a number of research work with The Shona Language and Culture Association where she is currently the national treasurer.

Mika Nyoni is a Senior Lecturer in English at Great Zimbabwe University, Faculty of Education, Department of Curriculum Studies. His main research interests are in Sociolinguistics, Language Pedagogy and Literature. He has vast experience in language teaching at High School, College and University levels spanning a period of over two decades. Besides publishing academic papers he has published opinion papers and short stories in local newspapers and has recently contributed nineteen poems to the anthology From where the wind blows (2012). 